\title{
CONCEPT OF SELFMAINTAINING VEHICLES
}

\author{
Srdjan Filipović ${ }^{*}$, Nada Stanojević ${ }^{2}$, Davor Vujanović ${ }^{3}$, Miloš Vasić ${ }^{4}$, Goran Šiniković ${ }^{2}$ \\ ${ }^{1}$ PUC "Komunalne suzbe", Pozarevac, Serbia \\ ${ }^{2}$ University of Belgrade, Faculty of Mechanical Engineering, Serbia \\ ${ }^{3}$ University of Belgrade, Faculty of Traffic and Transportation, Serbia \\ ${ }^{4}$ Institute for research and design in industry, Serbia
}

\begin{abstract}
Main task of this paper is to present idea of selfmaintaining and make corresponding concept of selfmaintaining vehicles. Through setting parameters of selfmaintaining and providing algorithm of selfmaintenance in vehicles author made attempt to set basic principles in this area of research. Paper presents researched suitability of different drivetrains of vehicles for selfmaintaining. Also, convenient artificial intelligence model for selfmaintaining was reviewed and discussed. Paper discuss near future and future development of maintenance of the vehicles according to presence of mechanical and electrical components. Conclusions made in this papers describes possible ways of future development of maintenance.
\end{abstract}

Key words: maintenance, selfmaintenance, artificial intelligence, vehicle selfmanagent

\section{INTRODUCTION}

Maintenance of the vehicles is set of usually complex actions in order to keep obtain vehicle's reliability within defined range. These actions consist of design, projected maintenance and set of maintenance actions during life cycle of the vehicle. [1], [2]

Nowadays It is performed by educated and highly trained personnel. Complexity of the vehicle defines complexity of maintenance.

As maintenance of the vehicle must be conducted in the way that suits purpose, resources and efficiency of the vehicle which is maintained, it has to be managed. [3]

Maintenance of the vehicle is managed by owner, by user, by producer, by system etc. and consists of use of sublimated wide empiria of design, production and desired performance of the maintained vehicle. Also it requires maintenance empiria of system itself, skills and knowledge in micro and macro technology of maintenance methodologies and techniques.

All of this was performed or managed by men, up to now!

\section{DEFINITION OF SELFMAINTAINING VEHICLES}

Maintenance has quite a lot of definition but one can describe maintenance of the vehicle as necessary action/ actions which has to be performed on vehicle in order obtain vehicle's reliability in desired margins of working state. [4]

Selfmaintaining vehicle should do maintenance by itself or with some assistance of manually or automated operated process. Actions has to be performed by the vehicle.

In that matter of approach [5], [6], we can divide several types of selfmaintaining:

1. selfmaintaining vehicle,
2. selfmaintaining ready vehicle,

3. semi selfmaintaining vehicle,

4. assisted selfmaintenance of the vehicle.

Selfmaintaining vehicle should operate all maintenance by itself. This could be achieved with proper maintenance procedures, Artificial intelligence and preventive maintenance which uses for example aggregate replacement. Modular construction of the vehicle should provide constructive and maintenance stations operational ability.

Selfmaintenance ready vehicles when maintenance procedures are made by third party equipment in maintenance stations making one equipment used for many vehicles.

Semi-selfmaintaining vehicle operate some maintenance procedures by itself and other by maintenance personnel. Sub division of this type can be done by complexity of actions and level of making maintenance decision. [7], [8]

1. vehicle maintenance decision,

2. operator maintenance decision,

3. combined.

Assisted selfmaintenance of the vehicle is maintenance assisted by men by doing actions or making decisions when or what to perform "on vehicle" or "off vehicle" either presence of the vehicle in the maintenance station is necessary or not via relay connection.

Also, we can divide selfmaintenance by the level of performing actions on:

1. macro level selfmaintenance,

2. micro level selfmaintenance,

3. combined selfmaintenance (macro + micro level + projected maintenance). 
Macro level selfmaintenance consists of macro level actions like aggregate or part replacement or repair.

Micro level selfmaintenance consists of actions on micro level like usage of self healing materials, nano materials, nano robots and design and construction actions (maintenance free or renewable parts)

Projected maintenance consists of actions and solutions used in vehicle design process in order to achive better maintenance qualities.

Since maintenance has to be managed it has to be managed by vehicle's selfmanagement. Vehicles self management should engage artificial intelligence as decision maker. Hence, the Artificial Intelligence is necessity.

\section{ARTIFICIAL INTELLIGENCE}

Artificial intelligence (Al) is an area of computer science that emphasizes the creation of intelligent machines that work and react like humans. [9] Some of the activities computers with artificial intelligence are designed for include:
- speech recognition,
- learning,
- planning,
- problem solving.

The following $\mathrm{Al}$ techniques can be used in machinery solving problem:

1. neural network (NN),

2. fuzzy logic (FL),

3. genetic algorithm (GA).

Neural network, or ANN, covers in the production surprisingly large and various areas: design of production systems and processes to the management of production systems and processes. ANN have been recognized as an indispensable tool whose implementation can be achieved by: improving product quality, increase productivity, reducing system response time, increase reliability and so on.

ANN are simplified mathematical models of human brain function, artificial neural network is attempted imitation of biological neural networks. With a view of the structure, neural networks are divided into static (or feedforward) and dynamic (or feedback), depending on the model of neurons from which they were built, and by way of signal propagation through the network.

Fuzzy logic and fuzzy inference system (FIS) is an effective technique for the identification and control of complex non-linear systems. For prediction, fuzzy logic is used. The theory of fuzzy logics, initiated by Zadeh has proved to be useful for dealing with uncertain and vague information. Fuzzy logic is particularly attractive due to its ability to solve problems in the absence of accurate mathematical models. This theory has proved to be an effective means for dealing with objectives that are linguistically specified. Linguistic terms, such as 'low,' 'medium' and 'high' may be defined by fuzzy sets. The pro- cess of fuzzy inference involves membership functions, fuzzy logic operators, and if then rules. The basic structure of a FIS consists of three conceptual components: a rule base, which contains a selection of fuzzy rules; a database which defines the membership functions (MF) used in the fuzzy rules; and a reasoning mechanism, which performs the inference procedure upon the rules to derive an output.

Adaptive Neuro-Fuzzy Inference System (ANFIS) is using a given input/output data set, the toolbox function anfis constructs a fuzzy inference system (FIS) whose membership function parameters are tuned (adjusted) using either a back propagation algorithm alone or in combination with a least squares type of method. This adjustment allows your fuzzy systems to learn from the data they are modeling. A network-type structure similar to that of a neural network. The entire system architecture consists of five layer, namely, the fuzzy layer and total output layer. Five network layers are used by ANFIS to perform the following fuzzy inference steps: (i) input Fuzzification, (ii) fuzzy set database construction, (iii) fuzzy rule base construction, (iv) decision making, and (v) output defuzzification. ANFIS is more powerful than the simple fuzzy logic algorithm and neural networks.

Genetic algorithms (GA) mimics the process of natural evolution by incorporating the "survival of the fittest" philosophy. In GA, a point in search space (binary or decimal numbers) known as chromosome. A set of chromosomes is called population. A population is operated by three fundamental operations:

1. reproduction (to replace the population with large number of good strings having high fitness values)

2. crossover (for producing new chromosomes by combining the various pairs of chromosomes in the population),

3. mutation (for slight random modification of chromosomes).

According to various authors, NN/ANN have become an indispensable tool in the solving of tasks related to production processes. Bettermore, the ANFIS with artificial pre learned instructions and fuzzy logic that can from the data they are modeling, can be the most interesting model.

\section{ALGORITHM OF SELFMAINTENANCE}

Algorithm of selfmaintenance can be presented in six major components.

1. inputs,

2. maintenance procedures,

3. maintenance actions,

4. vehicles actions,

5. schedule,

6. al Maintenance.

Inputs are defined by driver, environment and vehicle. 
Artificial Intelligence maintenance detects and qualify, diagnose, predict and react (feedback). It relay on logical deduction.

Maintenance actions are defined by maintenance method and dependable of environment, exploitation and purpose of the vehicle.

Maintenance procedures are defined by maintenance model or method used.

Schedule is defined by complexity of the vehicle, work conditions and can be time line, 2D or 3D matrix

Vehicle actions are made according to maintenance and driving management

All components and their relationships can be illustrated in simple algorithm presented in Figure 1.

Several models of Al maintenance can be made:

1. universal model,

2. maintenance method defined model,

3. flexible/Al dependant model.

\section{MODERN VECHICLES DRIVE TYPES AND EXPECTED DEVELOPMENT}

In the time of this paper there are several drive types commonly used to propel the vehicle [10], [11], [12]:

1. Internal Combustion Engine Vehicles (ICEV)

- Petrol powered

- LPG powered

- Diesel powered

2. Hybrid Electric Vehicles (HEV)

3. Plug-in Hybrid Electric Vehicles (PHEV)

4. Battery Electric Vehicles (BEV)

- Battery cells

- Super capacitors

- Solar power

5. Fuel Cell Electric Vehicles (FCEV)

Near future

1. Hybrid Electric Vehicles (HEV)

2. Plug-in Hybrid Electric Vehicles (PHEV)

3. Battery Electric Vehicles (BEV)

- Battery cells

- Super capacitors

- Solar power

4. Fuel Cell Electric Vehicles (FCEV)

Future

1. Battery Electric Vehicles (BEV)

- Super capacitors

- Solar power

2. Fuel Cell Electric Vehicles (FCEV)

\section{SUITABILITY OF DIFFERENT DRIVETRAINS OF VEHICLES FOR SELFMAINTAINING}

Suitability of vehicle selfmaintability is reversely proportional to the complexity of the vehicles design and reliability of its components. [4] ,[10], [11], [12], [13], [14]

As the most complex component of the vehicle is its drivetrain we can set different values for different types of drivetrains and their needs for maintenance.

Need of maintenance is generated by the nature of components used in the drive train (mechanical, electrical, electronical, process...) and it is illustrated in the table bellow.

Obviously EV's with battery or super capacitors are vehicles with less maintenance needed compared with other types of propulsion. That is from fact that there are less mechanical and moving parts for example several thousand compared to several hundreds of parts which gives them better reliability and less maintenance action needed.

In the matter of maintenance this type of vehicles will be the choice of the future. Simplicity of design of BEVs is something car makers of the future will take in serious consideration because there will be less need for complicated procedures and highly competent technicians and engineers.

\section{CONCLUSION}

Selfmaintained vehicles as all selfmaintained machines demands selfmanaged maintenance. In that matter Artificial intelligence is necessity. Of all Al methods most suitable method is Adaptive Neuro-Fuzzy Inference System (ANFIS) according to the research experience.

Choosing suitable maintenance method or methods has to be compatible with vehicle and its drivetrain. As the future vehicles would be Self driving, Self Diagnostic, Self Maintained, Modular, Standardized, Artificial intelligent, and most of all in some sort electric powered special care has to be put on choosing right maintenance method of electric machinery (MIL HBK, etc).

Simplicity of BEV design and its maintainability lies in structure of vehicles with ratio of mechanical and electrical components. BEV maintainability lies in more percentage of electrical maintenance and less mechanical maintenance, because of Less moving parts-less friction, Less wear and tear maintenance and Modularity.

Another conclusion of this research shows that for future maintenance of the vehicles new techniques and methods for electromechanical maintenance should be developed along with self - diagnostics.

New materials like nano materials and its derivative should be developed and more used in future design and construction.

New drivetrain technologies includes batteries, hybrid components, fuel cells and its energy containers or 


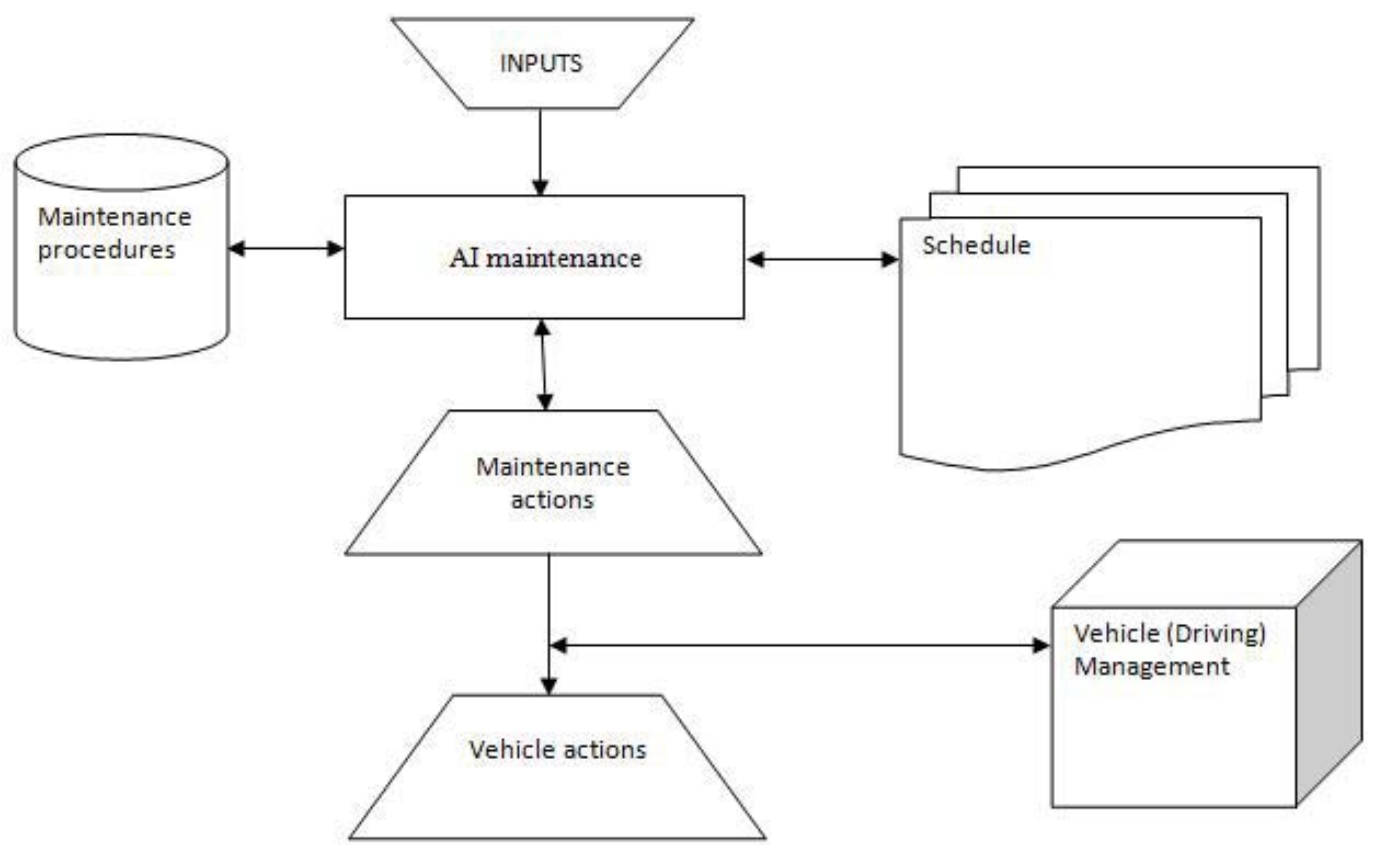

Figure 1: Basic algorithm of selfmaintenance

Table 1: Table of intensity criteria of maintenance need

\begin{tabular}{|l|c|c|c|c|}
\hline \multirow{2}{*}{ Drive type } & \multicolumn{3}{|c|}{ Need for maintenance } \\
\cline { 2 - 5 } & Petrol powered & Mechanical & Electrical & Process \\
\hline \multirow{3}{*}{$\begin{array}{l}\text { Internal Combustion Engine } \\
\text { Vehicles(ICEV) (SI) }\end{array}$} & LPG powered & $* * * *$ & $*$ & \\
\cline { 2 - 5 } & Diesel powered & $* * * *$ & $*$ & \\
\hline & & $* * * *$ & $* * *$ & \\
\hline Hybrid Electric Vehicles (HEV) & Battery cells & $*$ & $* * * *$ & $*$ \\
\hline Plug-in Hybrid Electric Vehicles (PHEV) EREV & $* * *$ & \\
\hline \multirow{2}{*}{$\begin{array}{l}\text { Battery Electric Vehicles } \\
\text { (BEV) }\end{array}$} & Super capacitors & $*$ & $* * *$ & \\
\cline { 2 - 5 } & Solar powered etc & $*$ & $* * *$ & \\
\hline
\end{tabular}

Note: intensity criteria ${ }^{*}$ very low; ${ }^{* *}$ low: ${ }^{* *}$ medium: ${ }^{* * *}$ high: ${ }^{* * * * *}$ very high

transmitters all of it demands Safety as imperative of maintenance of the vehicles.

Selfmaintained vehicles demands new maintenance technologies, methods, design and construction. Maintenance as branch of engineering will affected and has to transform from action level to project and research level of activity.

\section{REFERENCES}

1. Popović V., Vasić B., Petrović M. (2010) The possibility for FMEA method improvement and its implementation into bus life cycle", Strojniški Vestnik Journal of Mechanical Engineering 56 3, pp179-185 (UDC 658.56:629.34)
2. Vujanović D., Momčilović V., Medar O. (2018) Infl uence of an integrated maintenance management on the vehicle fleet energy efficiency", Thermal Science Vol. 22, No. 3, pp. 1525-1536 (https://doi. org/10.2298/TSCl170209122V)

3. Wilson A., de Bruin A., Eweg E., (2008) Guide to Maintenance Management, Hogeschool Utrecht, University of Applied Sciences, ISBN 978-90813466-1-0

4. Filipović S., Stanojević N. Vujanović.D. Vasić.M., 2018, CAPACITY TO CHOOSE ADEQUATE VEHICLE MAINTENANCE METHOD DEPENDING ON DRIVE TYPE, Zbornik radova 3rd Maintenance Forum, Belgrade ISBN 978-86-84231-43-9, pp 21-38 
5. Pedaste M., Mäeots M., Siiman L., de Jong T., van Riesen S., Kamp E., Manoli C., Zacharia Z., Tsourlidaki E. (2015) Phases of inquiry-based learning: Definitions and the inquiry cycle, Educational Research Review 14, pp 47-61, DOI (http://dx.doi. org/10.1016/j.edurev.2015.02.003)

6. Petropoulos F., Kourentzes N., Nikolopoulos K., Siemsen E. (2018) Judgmental selection of forecasting models", Journal of Operations Management 60 (2018) 34-46, DOI (https://doi.org/10.1016/j. jom.2018.05.005)

7. Prof. dr. Branko Vasić, (1997): Maintenance Management, NIRO“OMO“ ID55447564, Belgrade

8. Chałas K. (2014) Technical culture and human axjosphere, Advances in Science and Technology Research Journal 8(24):pp107-110, DOI:https://doi. org/10.12913/22998624/577

9. Kovač, P., Rodić, D., Pucovski, V., Mankova, I., Savkovic, B., Gostimirović, M. (2012), A review of artifi cial intelligence approaches applied in intelligent processes, Journal of Production engineering, vol 15 , No1

10. Mark A. Delucchi and Timothy E. Lipman (2010) Lifetime Cost of Battery, Fuel-Cell, and Plug-in Hybrid Electric Vehicles, University California Davis, University of California Berkley, ISBN 978-0-444-535658, DOI: 10.1016/B978-0-444-53565-8.00002-6
11. Bernd Propfe, Martin Redelbach, Danilo J. Santini, Horst Friedrich, (2012) Cost analysis of Plug-in Hybrid Electric Vehicles including Maintenance \& Repair Costs and Resale Values, Institute of Vehicle Concepts, German Aerospace Center (DLR), EVS26 Los Angeles, California, May, 2012

12. Hydrogen Fuel Cell Engines and Related Technologies: Rev 0, December (2001) Module 7: Fuelcell bus maintenance

13. Richard Raustad, (2017) Electric Vehicle Life Cycle Cost Analysis, Electric Vehicle Transportation Center, EVTC Report Number: FSEC-CR-2053-17

14. http://www.reliabilityeducation.com/ReliabilityPredictionBasics.pdf 